\title{
Klebsiella pneumoniae NUEVA DELHI METALO-BETALACTAMASA EN EL HOSPITAL NACIONAL DOS DE MAYO. LIMA, PERÚ
}

\author{
Cristhian Resurrección-Delgado ${ }^{1, a}$, Juan José Montenegro-Idrogo ${ }^{1,3, b}$, Alfredo Chiappe-Gonzalez ${ }^{1, a}$, \\ Renzo Vargas-Gonzales, ${ }^{1,3, b}$, Carolina Cucho-Espinoza ${ }^{2, c}$, Dick Henry Mamani-Condori',d, Luz María Huaroto-Valdivia ${ }^{2, c}$
}

\begin{abstract}
RESUMEN
La emergencia de enterobacterias productoras de carbapenemasas de tipo Nueva Delhi Metalo beta-lactamasas (NDM), representan, hoy en día, un verdadero problema de salud pública mundial. La presencia de este mecanismo de resistencia limita o anula las opciones terapéuticas para combatir a estas bacterias. En Latinoamérica, las cifras son cada vez más elevadas, pues se reportan en Guatemala, Colombia, Chile, Argentina, entre otros. Perú no ha descrito, hasta la fecha, la presencia de este patrón de resistencia; sin embargo, desde hace varios años se presume de su existencia. Se describen nueve casos de Klebsiella pneumoniae NDM, como agentes infecciosos o colonizantes, en pacientes críticamente enfermos, en su mayoría con patología neuroquirúrgica, del Hospital Nacional Dos de Mayo, en Lima - Perú. Los pacientes de la serie descrita a continuación, representan los primeros reportes de Klebsiella pneumoniae NDM en el Perú.
\end{abstract}

Palabras clave: Klebsiella pneumoniae, Nueva Delhi Metalo beta-lactamasa, Enterobacteriaceae, carbapenemasa, Latinoamérica. (fuente: DeCS BIREME).

\section{Klebsiella pneumoniae NEW DELHI METALO-LACTAMASE IN A PERUVIAN NATIONAL HOSPITAL}

\begin{abstract}
The emergence of Enterobacteria producing carbapenemases of type New Delhi Metalo beta-lactamases (NDM), represent, today, a real problem of world public health. The presence of this resistance mechanism limits or nullifies the therapeutic options to combat these bacteria. In Latin America, the figures are getting higher, as they are reported in Guatemala, Colombia, Chile, Argentina, among others. Peru has not, to date, described the presence of this resistance pattern; however for several years it has been presumed to exist. Nine cases of Klebsiella pneumoniae NDM are described, as infectious or colonizing agents, in critically ill patients, mostly with neurosurgical pathology, of Hospital Nacional Dos de Mayo in Lima - Peru. The patients in the series described below represent the first reports of Klebsiella pneumoniae NDM in Peru.
\end{abstract}

Key words: Klebsiella pneumoniae, New Delhi Metallo beta-lactamases, Enterobacteriaceae, carbapenemasas, Latin America. (source: MeSH NLM).

\section{INTRODUCCIÓN}

Actualmente, la emergencia de enterobacterias productoras de carbapenemasas (CPE) en el ámbito hospitalario, representa un verdadero problema de salud pública mundial, especialmente cuando se hace referencia a la Nueva Delhi Metalo beta-lactamasa (NDM) ${ }^{(1-4)}$. El subtipo más frecuente de esta enzima es la NDM-1, codificada por el gen de origen plasmídico blaNDM-1. La NDM-1, es una carbapenemasa transferible perteneciente a la clase molecular B de la clasificación de Ambler, caracterizándose por presentar zinc en su sitio activo y pudiendo hidrolizar a todos los beta-lactámicos, a excepción de los monobactámicos ${ }^{(5,6)}$. Así mismo, las bacterias NDM-1, suelen cursar con otros mecanismos de resistencia frente a antibióticos de diversas familias,

\footnotetext{
Servicio de Enfermedades Infecciosas y Tropicales, Hospital Nacional Dos de Mayo. Lima, Perú.

Servicio de Microbiología, Hospital Nacional Dos de Mayo. Lima, Perú.

Facultad de Medicina. Universidad Nacional Mayor de San Marcos. Lima, Perú.

Médico infectólogo; ${ }^{\mathrm{b}}$ médico residente de Infectología; ${ }^{\mathrm{c}}$ médico patólogo clínico; ${ }^{\mathrm{d}}$ tecnólogo médico

Recibido: 04/01/2017 Aprobado: 24/05/2017 En línea: 28/06/2017
}

Citar como: Resurrección-Delgado C, Montenegro-Idrogo JJ, Chiappe-González A, Vargas-Gonzales R, Cucho-Espinoza C, Mamani-Condori DH, et al. Klebsiella pneumoniae nueva Delhi metalo-betalactamasa en el hospital nacional Dos de Mayo. Lima, Perú .Rev Peru Med Exp Salud Publica. 2017;34(2):261-7. doi: 10.17843/rpmesp.2017.342.2615 
como fluoroquinolonas, aminoglucósidos, macrólidos y al trimetropin-sulfametoxazol; inclusive, algunos se han reportado como panresistentes ${ }^{(5-8)}$.

Las NDM se describieron por primera vez en el 2008, en un paciente sueco, el cual, al retornar de la India, presentó infección del tracto urinario por Klebsiella pneumoniae resistente a carbapenémicos ${ }^{\left({ }^{9}\right)}$. Desde entonces, las NDM se han reportado en todos los continentes, mostrando una rápida diseminación global ${ }^{(10,11)}$. En América Latina, el primer reporte data del año 2011, cuando dos cepas de $K$. pneumoniae NDM-1, se aislaron de pacientes pediátricos en Guatemala, sin histórico de viajes ${ }^{(12)}$. Dos años después, en Colombia, se presenta un nuevo brote por el mismo agente en seis neonatos, representando los primeros reportes de NDM en Sudamérica ${ }^{(13)}$.

A pesar que fueron inicialmente descritas en Klebsiella pneumoniae, también se les halla en otras enterobacterias como Escherichia coli y Enterobacter cloacae, al igual que en no enterobacterias, como Acinetobacter ${ }^{(14)}$. Finalmente, también han sido identificadas en bacterias altamente virulentas como Vibrio cholerae y Shigella boydii ${ }^{(8)}$.

El amplio perfil de resistencia que el gen blaNDM-1 confiere a la bacteria, dificulta y limita las opciones terapéuticas contra estos patógenos ${ }^{(14)}$. A continuación, presentamos las características de una serie de nueve pacientes con aislamiento, en once muestras biológicas, de Klebsiella pneumoniae productora de carbapenemasa tipo NDM, en un grupo de pacientes críticamente enfermos del Hospital Nacional Dos de Mayo, durante el año 2016, representando el primer reporte de Klebsiella pneumoniae NDM en Perú.

\section{METODOLOGÍA}

\section{DISEÑO DE ESTUDIO Y POBLACIÓN}

Estudio descriptivo de serie de casos en el Hospital Nacional Dos de Mayo, hospital de tercer nivel de atención y centro de referencia nacional localizado en Lima, Perú. La capacidad aproximada es de 640 camas para internamiento. Brinda atención en especialidades médicas y quirúrgicas, al igual que atención ambulatoria, a través de consultorios externos, servicio de emergencia y cuidados críticos las 24 horas del día. Se incluyeron pacientes con cultivos positivos a Klebsiella pneumoniae resistente a carbapenémicos (KPRC).

CULTIVOS BACTERIANOS, DETERMINACIÓN DE PRODUCCIÓN DE BETA-LACTAMASA DE ESPECTRO EXTENDIDO (BLEE) Y DETECCIÓN MOLECULAR DE CARBAPENEMASAS

El laboratorio de microbiología procesó once muestras en los siguientes medios de cultivo:

\section{MENSAJES CLAVE}

Motivación para realizar el estudio. La resistencia a antimicrobianos es un problema emergente a nivel global. Las enterobacterias (E. coli, Klebsiella) resistentes a carbapenémicos en Perú, tiene nula evidencia, su manejo es limitado y poco efectivo.

Principales hallazgos. Se describen nueve pacientes con aislamiento de Klebsiella-NDM resistente a carbapenémicos, confirmada por métodos moleculares en nuestro hospital. La exposición a antibióticos de amplio espectro fue común como la estancia hospitalaria prolongada.

Implicancias. Es la primera serie de pacientes con aislamiento de enterobacteria resistente a carbapenémicos (Klebsiella productora de carbapenemasa NDM), evidenciándose problemas en diagnóstico y manejo oportuno de estas.

Secreción de herida (1): agar sangre, Mac Conkey, azida de sodio y manitol salado. Urocultivo (4): agar Cled. Punta de catéter (2): agar sangre (método Maki). Aspirados bronquiales (3): agar sangre, Mac Conkey y manitol salado. Hemocultivo ${ }^{(1)}$ : sistema automatizado BACTEC FX, con positividad a las 12 horas y sembrado posteriormente en agar sangre y Mac Conkey.

Los medios fueron incubados a $37^{\circ} \mathrm{C}$ durante 24 horas, exhibiendo crecimiento de bacilos gram negativos corroborados con la tinción Gram. En nueve aislamientos se procedió a la identificación y sensibilidad en el analizador BD Phoenix TM 100. Este equipo realiza la metodología de fluorometría y cromogénica para la identificación. La susceptibilidad bacteriana de estas cepas se realizó por el método de microdilución, cuya lectura se basa en el indicador de actividad metabólica redox y cambios en la turbidez, obteniendo la concentración inhibitoria mínima (CIM) para cada uno de los antibióticos evaluados, de acuerdo con las directrices del Clinical and Laboratory Standards Institute (CLSI) (M100S Performance Standards for Antimicrobial Susceptibility Testing 26th Ed).

Se identificó en estos nueve aislamientos Klebsiella pneumoniae, mostrando presencia fenotípica de betalactamasa de espectro extendido (BLEE), además de CIM elevados para ertapenem, meropenem e imipenem, activándose la alarma del equipo como "productor potencial de carbapenemasa".

Los otros dos aislamientos (orina y aspirado bronquial), fueron identificados por métodos manuales (medios diferenciales: citrato $(+)$, TSI $(\mathrm{A} / \mathrm{A})$, LIA $(\mathrm{K} / \mathrm{K})$, motilidad negativa, indol negativo), identificando Klebsiella pneumoniae. La susceptibilidad, en estos casos, se realizó por disco difusión, siguiendo los criterios del Manual CLSI 
26th Ed. Existió presencia de BLEE por la sinergia con el inhibidor (amoxicilina/ ácido clavulánico), cefotaxima y ceftazidima. La presencia de posible carbapenemasa se infirió por halos inhibitorios de $6 \mathrm{~mm}$ en imipenem (IMP) y meropemen (MEM), respectivamente.

El descarte de carbapenemasa se inició evaluando dos metodologías: a) Sinergia a doble disco con ácido fenilborónico (APB) y ácido etilendiamino tetraacético (EDTA), las que descartan carbapenemasas KPC (IMPAPB-MEM) o MBL (IMP-EDTA-MEM). b) Test de Hodge modificado (MHT) de acuerdo al Manual CLSI 26th Ed.

Los resultados del MHT fueron negativos, es decir, no concluyentes de carbapenemasas; mientras que la sinergia a doble disco fue positiva. Por ello, se optó por una tercera prueba, el método de inactivación de carbapenemasas (MIC) como alternativa al ensayo de
Hodge (CLSI 27th Ed), teniendo como control positivo Klebsiella pneumoniae ATCC BAA 1705 siendo KPC y una cepa control negativo Klebsiella pneumoniae ATCC BAA 1706 que corresponde a una cepa resistente a carbapenems por mecanismo no enzimáticos (Figura 1).

\section{CARACTERIZACIÓN MOLECULAR DE GENES DE RESISTENCIA A ANTIBIÓTICOS Y TIPIFICACIÓN MOLECULAR}

Todos los aislamientos del estudio fueron sometidos al laboratorio de microbiología del Instituto Nacional de Salud (INS) del Perú, como laboratorio de referencia para la confirmación molecular por PCR convencional de la producción del tipo de carbapenemasa en los aislamientos reportados, los primers utilizados fueron el NDM-1-F (GGAAAA CTT GAT GGA) y el NDM-1-R (TAA AAC GCC TCT GTC).

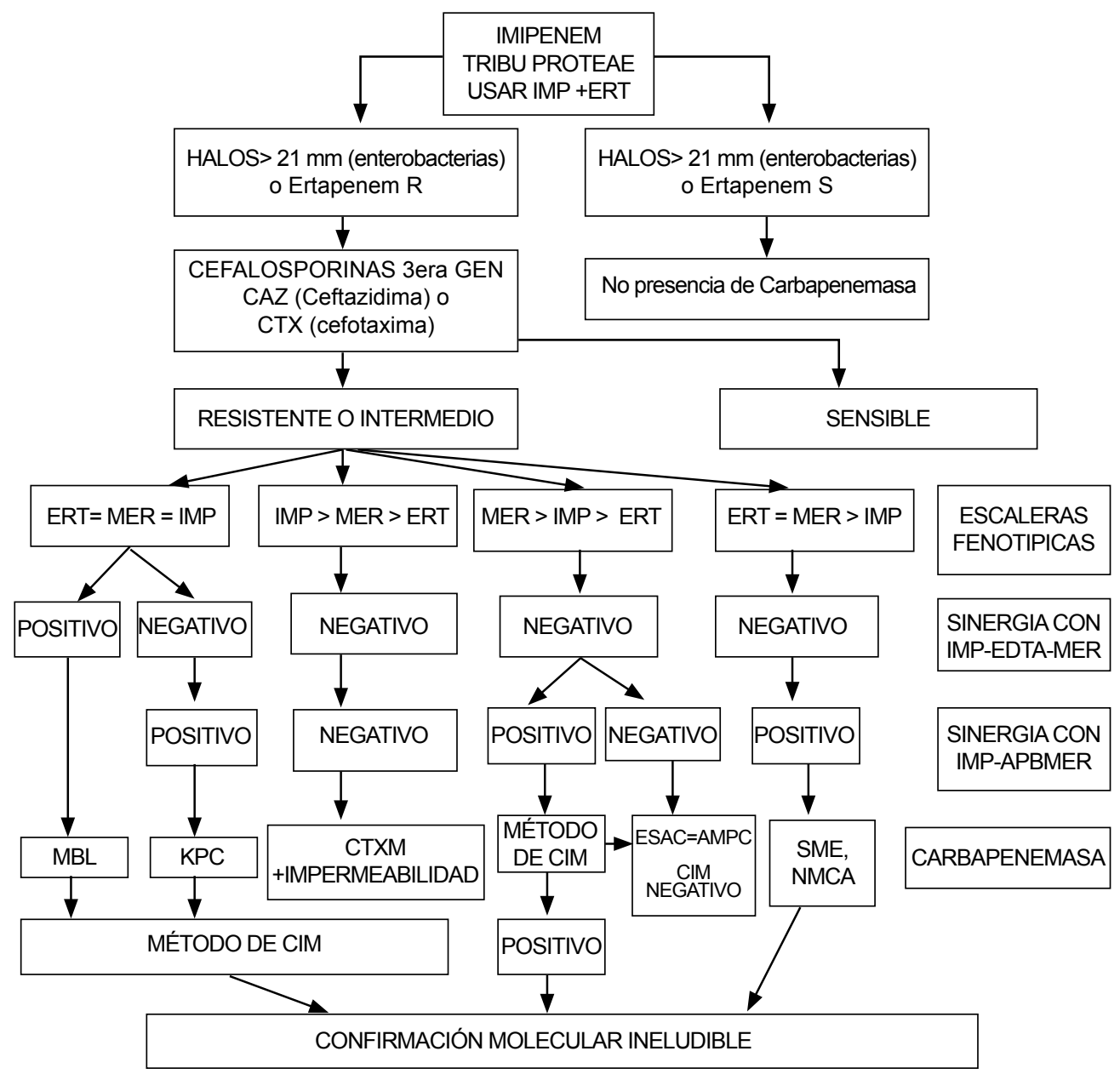

S: sensible; R: resistente; IMP: imipenem; MER: meropenem; ERT: ertapenem; AMPC: betalactamasa tipo C; CTXM: cefotaximasa; ESAC: AMPC espectro extendido; EDTA: ácido etilendiaminotetraacético; APB: ácido fenil borónico; CIM: Método Inactivación Carbapenemasa; Tipos de carbapenemasas: MBL: metalobetalactamasa, KPC, SME, NMCA

Adaptado de: Pasterán F. Instituto Nacional de Enfermedades Infecciosas. ANLIS “Dr. Carlos G. Malbrán”

Figura 1. Flujograma de detección de carbapenemasas 


\section{RESULTADOS}

\section{PACIENTES}

Nueve pacientes fueron documentados. Cuatro aislamientos fueron considerados como colonización y cinco como infección por KPRC. Cuatro eran varones, la mediana de edad fue 56 años. La mortalidad global fue $55,5 \% \mathrm{y}$, debido a la presencia de otras comorbilidades, no pudo calcularse la mortalidad atribuida. La mediana de tiempo entre la admisión y el aislamiento de KPRC fue 26 días (12-116 días) (Tabla 1 ).

En todos los aislamientos hubo detección fenotípica de BLEE, además de resistencias a carbapenémicos, inhibidores de betalactamasas, quinolonas, cotrimoxazol, y nitrofurantoína. En todos los cultivos hubo susceptibilidad antimicrobiana a amikacina $(\mathrm{CIM} \leq 8)$ (Tabla 2).
Los pacientes 2, 4, 6 y 7, al considerar el cultivo como colonizante, no recibieron antibioticoterapia. El paciente 8 falleció previo a la obtención de resultados de cultivos (aspirado bronquial y catéter venoso central). La característica común a todos los casos fue el pasaje por la sala de operaciones de emergencia (intervenciones neuroquirúrgicas, principalmente) y luego estancia prolongada en unidad de cuidados intensivos.

En dos pacientes existió internamiento en los seis meses previos. El caso 2, hospitalizado dos meses previos en el Hospital Regional de Ica, y el caso 9 referido del Hospital Regional de Huaraz, Ancash.

\section{MICROBIOLOGÍA}

El método de sinergia a doble disco presentó positividad con el disco de EDTA (IMP-EDTA-MEM), clasificándolas como metalo-betalactamasas y negativo a la sinergia con (MEM-APB-IMP).

Tabla 1. Características clínicoepidemiológicas de pacientes con Klebsiella pneumoniae NDM en el Hospital Nacional Dos de Mayo. Lima, Perú, 2016

\begin{tabular}{|c|c|c|c|c|c|c|c|c|c|c|c|}
\hline Paciente & Edad & Sexo & $\begin{array}{l}\text { Fecha } \\
\text { de } \\
\text { ingreso }\end{array}$ & $\begin{array}{l}\text { Fecha de } \\
\text { aislamiento }\end{array}$ & $\begin{array}{l}\text { Tto. ATB } \\
\text { previo }\end{array}$ & $\begin{array}{l}\text { Días hasta } \\
\text { aislamiento }\end{array}$ & $\begin{array}{l}\text { Diagnóstico } \\
\text { de ingreso }\end{array}$ & Muestra & Interpretación & Mortalidad & Tratamiento \\
\hline Caso 1 & 64 & M & $\begin{array}{c}\text { Febrero } \\
2016 \\
\text { [EMG] }\end{array}$ & $\begin{array}{l}\text { Mayo } 2016 \\
\text { [Cirugía] }\end{array}$ & $\begin{array}{l}\text { Ceftriaxona } \\
\text { Clindamicina } \\
\text { Meropenem }\end{array}$ & 85 & $\begin{array}{l}\text { Hemorragia } \\
\text { digestiva } \\
\text { (úlcera } \\
\text { duodenal) }\end{array}$ & $\begin{array}{l}\text { Secreción } \\
\text { de herida } \\
\text { operatoria }\end{array}$ & Infección & Vivo & $\begin{array}{c}\text { Colistina + } \\
\text { aminoglucósidos }\end{array}$ \\
\hline Caso 2 & 62 & $\mathrm{~F}$ & $\begin{array}{c}\text { Mayo } \\
2016 \\
\text { [EMG] }\end{array}$ & $\begin{array}{l}\text { Junio } 2016 \\
\text { [Cirugía] }\end{array}$ & $\begin{array}{l}\text { Piperacilina/ } \\
\text { Tazobactam }\end{array}$ & 28 & HSA Fisher III & Orina & Colonización & Fallecido & No \\
\hline Caso 3 & 44 & $\mathrm{~F}$ & $\begin{array}{l}\text { Mayo } \\
2016 \\
\text { [EMG] }\end{array}$ & $\begin{array}{l}\text { Junio } 2016 \\
\text { [Medicina] }\end{array}$ & $\begin{array}{l}\text { Ceftazidima } \\
\text { Ciprofloxacino } \\
\text { Clindamicina }\end{array}$ & 23 & $\begin{array}{l}\text { Sepsis: NIH } \\
\text { vs ITU }\end{array}$ & Orina & Infección & Fallecido & No \\
\hline Caso 4 & 55 & $\mathrm{~F}$ & $\begin{array}{l}\text { Julio } \\
2016 \\
\text { [EMG] }\end{array}$ & $\begin{array}{l}\text { Agosto } \\
2016 \\
\text { [UTNI] }\end{array}$ & $\begin{array}{l}\text { Ceftazidima } \\
\text { Amikacina }\end{array}$ & 22 & HSA Fisher IV & Orina & Colonización & Vivo & No \\
\hline Caso 5 & 53 & M & $\begin{array}{l}\text { Agosto } \\
2016 \\
\text { [UTNI] }\end{array}$ & $\begin{array}{l}\text { Agosto } \\
2016 \\
\text { [UCIN] }\end{array}$ & $\begin{array}{l}\text { Meropenem } \\
\text { Vancomicina }\end{array}$ & 12 & $\begin{array}{c}\text { Stroke } \\
\text { hemorrágico, } \\
\text { PO DVE }\end{array}$ & $\begin{array}{l}\text { Aspirado } \\
\text { bronquial }\end{array}$ & Infección & Fallecido & No \\
\hline Caso 6 & 48 & $\mathrm{~F}$ & $\begin{array}{l}\text { Abril } \\
2016 \\
\text { [EMG] }\end{array}$ & $\begin{array}{l}\text { Agosto } \\
2016 \\
\text { [UCl] }\end{array}$ & $\begin{array}{l}\text { Meropenem } \\
\text { Vancomicina }\end{array}$ & 116 & $\begin{array}{l}\text { Micetoma } \\
\text { ápice } \\
\text { izquierdo }\end{array}$ & $\begin{array}{l}\text { Aspirado } \\
\text { bronquial }\end{array}$ & Colonización & Vivo & No \\
\hline Caso 7 & 56 & M & $\begin{array}{l}\text { Agosto } \\
2016 \\
\text { [EMG] }\end{array}$ & $\begin{array}{c}\text { Septiembre } \\
2016 \\
\text { [UCIN] }\end{array}$ & $\begin{array}{l}\text { Meropenem } \\
\text { Vancomicina }\end{array}$ & 28 & $\begin{array}{c}\text { Chock } \\
\text { hemorrágico, } \\
\text { hematoma } \\
\text { cerebral }\end{array}$ & Punta CVC & Colonización & Vivo & No \\
\hline Caso 8 & 65 & $\mathrm{~F}$ & $\begin{array}{l}\text { Agosto } \\
2016 \\
\text { [EMG] }\end{array}$ & $\begin{array}{c}\text { Septiembre } \\
2016 \\
\text { [UTNI] }\end{array}$ & Ceftazidima & 13 & $\begin{array}{l}\text { Stroke } \\
\text { hemorrágico } \\
\text { Fisher III }\end{array}$ & $\begin{array}{l}\text { CVC y } \\
\text { Aspirado } \\
\text { bronquial }\end{array}$ & Infección & Fallecido & No \\
\hline Caso 9 & 90 & $M$ & $\begin{array}{l}\text { Agosto } \\
2016 \\
\text { [EMG] }\end{array}$ & $\begin{array}{c}\text { Septiembre } \\
2016 \\
\text { [UTNI] }\end{array}$ & $\begin{array}{l}\text { Meropenem } \\
\text { Vancomicina }\end{array}$ & 26 & $\begin{array}{c}\text { TEC } \\
\text { moderado: } \\
\text { Hematoma } \\
\text { subdural, } \\
\text { craneotomía } \\
\text { evacuación }\end{array}$ & Hemocultivo & Infección & Fallecido & $\begin{array}{c}\text { Colistina + } \\
\text { aminoglucósidos }\end{array}$ \\
\hline
\end{tabular}

EMG: Servicio de emergencia; UCl: unidad de cuidados intensivos; UTNI: unidad de cuidados intensivos neurológicos; UCIN: unidad de cuidados intermedios; UCICV: UCI cardiovascular; HSA: hemorragia subaracnoidea; CVC: catéter venoso central; PO DVE: posoperado derivación ventricular externa; Tto: tratamiento; ATB: antibiótico; NIH: neumonía intrahospitalaria; ITU: infección del tracto urinario 
Tabla 2. Perfil de susceptibilidad antimicrobiana de aislamientos de Klebsiella NDM de pacientes reportados del Hospital Nacional Dos de Mayo. Lima, Perú, 2016

\begin{tabular}{|c|c|c|c|c|c|c|c|c|c|c|c|}
\hline \multirow[b]{2}{*}{ Susceptibilidad } & \multirow{2}{*}{$\begin{array}{c}\text { Caso } 1 \\
\begin{array}{c}\text { Secreción } \\
\text { herida }\end{array}\end{array}$} & \multirow{2}{*}{$\frac{\text { Caso } 2}{\text { Orina }}$} & \multirow{2}{*}{$\frac{\text { Caso } 3}{\text { Orina }}$} & \multirow{2}{*}{$\frac{\text { Caso } 4}{\text { Orina }}$} & \multirow{2}{*}{$\begin{array}{c}\text { Caso } 5 \\
\text { Aspirado } \\
\text { bronquial }\end{array}$} & \multicolumn{2}{|c|}{ Caso 6} & \multirow{2}{*}{$\frac{\text { Caso } 7}{\text { CVC }}$} & \multicolumn{2}{|c|}{ Caso 8} & \multirow{2}{*}{$\frac{\text { Caso } 9}{\text { Hemocultivo }}$} \\
\hline & & & & & & Orina & $\begin{array}{l}\text { Aspirado } \\
\text { bronquial }\end{array}$ & & CVC & $\begin{array}{l}\text { Aspirado } \\
\text { bronquial }\end{array}$ & \\
\hline Amikacina & $\leq 8$ & $\leq 8$ & $\leq 8$ & $\leq 8$ & $\leq 8$ & $S$ & $S$ & $\leq 8$ & $\leq 8$ & $\leq 8$ & $\leq 8$ \\
\hline Gentamicina & $>8$ & $>8$ & $>8$ & $>8$ & --- & $\mathrm{R}$ & $\mathrm{R}$ & $>8$ & $>8$ & $>8$ & $>8$ \\
\hline $\begin{array}{l}\text { Amoxicilina/Ac } \\
\text { clavulámico }\end{array}$ & $\mathrm{R}$ & $>16 / 8$ & $>16 / 8$ & $>16 / 8$ & $\mathrm{R}$ & $\mathrm{R}$ & $\mathrm{R}$ & $\mathrm{R}$ & $\mathrm{R}$ & $\mathrm{R}$ & $\mathrm{R}$ \\
\hline $\begin{array}{l}\text { Ampicilina/ } \\
\text { sulbactam }\end{array}$ & $>16 / 8$ & -- & --- & --- & $>16 / 8$ & --- & $\mathrm{R}$ & $>16 / 8$ & $>16 / 8$ & $>16 / 8$ & $>16 / 8$ \\
\hline $\begin{array}{l}\text { Piperacilina/ } \\
\text { Tazobactam }\end{array}$ & $>64 / 4$ & $>64 / 4$ & $>64 / 4$ & $>64 / 4$ & $>64 / 4$ & $\mathrm{R}$ & $\mathrm{R}$ & $>64 / 4$ & $>64 / 4$ & $>64 / 4$ & $>64 / 4$ \\
\hline Cefazolina & --- & $>16$ & $>16$ & $>16$ & $>16$ & $\mathrm{R}$ & $\mathrm{R}$ & $>8$ & $>8$ & $>8$ & $>8$ \\
\hline Cefoxitin & $>16$ & $>16$ & --- & $>16$ & --- & $\mathrm{R}$ & $S$ & --- & $\mathrm{R}$ & --- & --- \\
\hline Ceftriaxona & $>16$ & $>4$ & $>4$ & $>4$ & $>4$ & --- & $\mathrm{R}$ & $>4$ & $>4$ & $>4$ & $>4$ \\
\hline Ceftazidima & $>16$ & $>16$ & $>16$ & $>16$ & $>16$ & $\mathrm{R}$ & $\mathrm{R}$ & $>16$ & $>16$ & $>16$ & $>16$ \\
\hline Cefepime & $>16$ & 8 & 16 & $>16$ & -- & --- & $r$ & $>16$ & 16 & 16 & $>16$ \\
\hline Ciprofloxacino & $>2$ & 2 & 2 & $>2$ & 2 & $r$ & $r$ & 2 & 2 & 2 & 2 \\
\hline Levofloxacino & 2 & $\leq 1$ & $\leq 1$ & $>4$ & $\leq 1$ & S & $S$ & $\leq 1$ & $\leq 1$ & $\leq 1$ & $\leq 1$ \\
\hline Norfloxacino & $\mathrm{R}$ & 8 & 4 & $>8$ & --- & $r$ & --- & --- & --- & --- & --- \\
\hline Aztreonam & $\mathrm{R}$ & --- & --- & $\mathrm{R}$ & $\mathrm{R}$ & $\mathrm{R}$ & $\mathrm{R}$ & $S$ & $\mathrm{R}$ & $\mathrm{R}$ & $\mathrm{R}$ \\
\hline Ertapenem & $>1$ & $>8$ & --- & $>2$ & $>1$ & $\mathrm{R}$ & --- & $>1$ & $>1$ & $>1$ & $>1$ \\
\hline Imipenem & $>8$ & $>8$ & $>8$ & $>8$ & --- & --- & --- & $>8$ & 8 & 8 & $>8$ \\
\hline Meropenem & $>32$ & $>8$ & 4 & $>8$ & $r$ & $\mathrm{R}$ & $\mathrm{R}$ & $>32$ & 4 & 4 & $>32$ \\
\hline Nitrofurantoina & $\mathrm{R}$ & --- & --- & $>64$ & $\mathrm{R}$ & $\mathrm{R}$ & $r$ & $r$ & $r$ & $r$ & $\mathrm{R}$ \\
\hline TMP/SMX & $<0,5 / 9,5$ & $>2 / 38$ & $>2 / 38$ & $>2 / 38$ & $>2 / 38$ & $\mathrm{R}$ & $\mathrm{R}$ & $>2 / 38$ & $>2 / 38$ & $>2 / 38$ & $>2 / 38$ \\
\hline BLEE & Sí & Sí & Sí & Sí & Sí & Sí & Sí & Sí & Sí & Sí & Sí \\
\hline bla NDM & Sí & Sí & Sí & Sí & Sí & Sí & Sí & Sí & Sí & Sí & Sí \\
\hline
\end{tabular}

Resultados método disco-difusión (R: resistente; r: intermedio; S: sensible); Valores numéricos: MICs (Resultados método BD Phoenix 100); ---: no data; TMP/SMX: trimetropin/sulfametoxazol; BLEE: producción de b- lactamasa de espectro extendido; blaNDM: cepa productora de metalo carbapenemasa NDM (método PCR), CVC: catéter venoso central.

Los resultados del MHT no fueron concluyentes para la detección de carbapenemasas, evidenciando, ocasionalmente, falsos positivos. Esta prueba es negativa cuando se tratan de lipoproteínas como metalobetalactamasas tipo NDM.

Se realizó el MIC como técnica alternativa a MHT y evidenció, en los once aislamientos, presencia enzimática, informándose como metalo-betalactamasa, y remitidas al INS para confirmación molecular y tipificación, en todos los casosm siendo reportada como cepas productoras de carbapenemasa tipo NDM. No se pudo evaluar clonalidad en las cepas descritas.

\section{DISCUSIÓN}

Los primeros reportes de CPE datan de 1996, cuando en Carolina del Norte en Estados Unidos, se reporta el aislamiento de Klebsiella pneumoniae resistente a carbapenémicos, debido a la presencia de una carbapenemasa denominada KPC-1 (15). En Latinoamérica, esta enzima se notifica por vez primera, en el año 2005 en Colombia, en dos pacientes sin historia de viajes fuera del país, tratándose de carbapenemasas tipo KPC-2 y tras lo cual, este tipo de enzimas se extendieron rápidamente por, prácticamente, toda Sudamérica ${ }^{(16)}$. En el Perú, el primer reporte de KPC se le atribuye al Hospital Nacional Arzobispo Loayza, quienes notifican, en el 2013, el aislamiento en hemocultivo de Klebsiella pneumoniae $\mathrm{KPC}$, en una paciente con lupus eritematoso sistémico y hemodiálisis ${ }^{(17)}$.

La presencia de carbapenemasas NDM-1 en Latinoamérica, se inició en el 2011, en Guatemala, y en el 2013 en Colombia. Posteriormente, al igual que las KPC, se diseminaron prontamente por todo el subcontinente americano ${ }^{(12,13)}$. En América latina, Klebsiella pneumoniae es la principal productora de KPC y NDM-1, sin embargo, estas carbapenemasas también han sido descritas, con menor frecuencia, en otras bacterias como E. coli, Acinetobacter baumanii, Enterobacter cloacae, entre otros. 
En el Perú no se ha descrito, hasta la fecha casos de Klebsiella pneumoniae NDM, sin embargo, luego del reporte de KPC del Hospital Antonio Lorena (HNAL) del Cusco, en marzo de 2016, la Dirección Regional de Salud de Cusco, reporta el aislamiento de Klebsiella pneumoniae resistente a carbapenémicos, en el servicio de medicina del HNAL, sin la identificación del mecanismo de resistencia implicado (18). Ello nos induce a reflexionar que, probablemente, el patrón de resistencia de tipo KPC o NDM, se halle circulando desde algunos años en nuestro país, pero debido a la falta de experticia para la sospecha, y la escasez de recursos apropiados para la identificación, posiblemente exista una infraestimación de los reportes.

La serie de casos descrita representa la primera y la mayor serie de casos presentada en el país relacionada a Klebsiella pneumoniae CPE-NDM. En nuestra serie, todos los pacientes fueron mayores de 40 años y habían sido atendidos por el servicio de emergencia; $5 / 9(55,5 \%)$ tuvieron intervención neuroquirúrgica y $4 / 9$ $(44,4 \%)$ fueron catalogados como colonizantes (dos urocultivos, un cultivo de punta de catéter y un cultivo de aspirado bronquial). En la descripción más grande de carbapenemasas NDM, descrita en el Reino Unido, hallaron que más del $60 \%$ fueron varones, en su mayoría mayores de 60 años y donde más del $50 \%$ presentaron historia previa de viaje o contacto con zonas de alta endemicidad ${ }^{(19)}$. En la presente serie no se encontró antecedente de viaje a zonas de alta endemicidad en ninguno de los casos. Por otro lado, más del $50 \%$ de nuestros pacientes fueron de sexo femenino, contrastando con los datos previamente mencionados. Así mismo, el uso previo de antibióticos, en su mayoría de amplio espectro, fue frecuente en los pacientes de nuestra serie.

A diferencia de otras series, las cepas aisladas en el nosocomio estudiado, mostraron susceptibilidad a amikacina, lo cual no es un patrón fenotípico usual de este tipo de carbapenemasa ${ }^{(13,20)}$. Ello podría indicar que se trataría de una nueva cepa, con diferente genotipo de los ya conocidos, lo cual requiere un mayor análisis a través de pruebas moleculares. El difícil acceso a técnicas más complejas en nuestra realidad, no hizo posible la confirmación de esta hipótesis. De igual manera, no se logró determinar el subtipo de NDM por las razones previamente descritas.

Por otro lado, la especificidad y sensibilidad del MHT son muy bajas para la identificación de metalobetalactamasa tipo NDM, en comparación con las serincarbapenemasas y carbapenemasas tipo OXA.

Frente a un brote de CPE, deben aplicarse medidas de prevención y control con prontitud, y son de vital importancia los programas de control de infecciones, el uso racional de antibióticos y un bien equipado laboratorio de microbiología que contenga métodos de identificación rápida de carbapenemasas, los cuales deben estar alertas en la identificación microbiológica y en el reconocimiento de casos colonizados o infectados. En nuestro escenario, los esfuerzos de investigación y control estuvieron orientados a la sala de operaciones de neurocirugía.

El patrón de susceptibilidad de las CPE brinda opciones terapéuticas escasas. Actualmente, la evidencia se basa en series de casos y recomendaciones de expertos. Dichas opciones incluyen combinaciones de, al menos, dos de los siguientes antibióticos: colistina, polimixina $\mathrm{B}$, fosfomicina, carbapenem (cuando la $\mathrm{CIM} \leq 8$ ), amikacina y tigeciclina. Además de los recientemente aprobados, ceftazidima/avibactam, especialmente para cepas productoras de KPC y ceftolozane/tazobactam. Sin embargo, estos dos últimos no tienen actividad contra las metalo-betalactamasas ${ }^{(14,20)}$.

No obstante, muchos antibióticos mencionados no se hallan disponibles en nuestro medio, como fosfomicina parenteral, polimixina $\mathrm{B}$, ceftazidima/avibactam y ceftolozane/tazobactam; mientras que colistina y tigeciclina se hallan fuera del petitorio nacional de medicamentos, dificultando el manejo de pacientes infectados. El asilamiento cada vez más frecuente de enterobacterias resistentes a carbapenémicos requiere el empleo rápido de dichos antimicrobianos, al igual que a los insumos de bioseguridad para aplicar medidas de control.

Finalmente, el uso antibiótico acarrea el incremento en costos de hospitalización. La CDC informó que en el año 2009 se gastaron 10700 millones de dólares en antibióticos en los EE.UU.

La serie publicada debe alertar a los sistemas institucionales de vigilancia epidemiológica a nivel nacional, para que estos monitoricen activamente los casos sospechosos a nivel local y adopten medidas preventivas contra la diseminación. El no control de estas cepas resistentes, culminará en la poca o nula disponibilidad de opciones terapéuticas y, por ende, en el incremento en la morbimortalidad de los pacientes.

Contribuciones de autoría: CRD, JJMI y RVG participaron en la concepción del artículo y, junto a ACG, realizaron la redacción. JJMI y RVG realizaron la recolección, resumen de los datos y complementaron la redacción. CCE, DHMC y LMHV realizaron el aislamiento microbiológico y la identificación de los mecanismos de resistencia de las cepas, posteriormente, junto a CRD y ACG, participaron en la revisión crítica del artículo. Todos aprobaron de la versión final.

Fuentes de financiamiento: autofinanciado.

Declaración de conflictos de interés: los autores declaran no tener conflictos de interés en la publicación de este artículo. 


\section{REFERENCIAS BIBLIOGRÁFICAS}

1. Khong W, Xia E, Marimuthu K, Xu W, Ying Teo Y, Tan E, et al. Local transmission and global dissemination of New Delhi Metallo-Beta-Lactamase (NDM): a whole genome analysis. BMC Genomics 2016;17:452. doi: 10.1186/s12864-016-2740-0.

2. Perez F, Endimiani A, Ray AJ, Decker BK, Wallace CJ, Hujer KM, et al. Carbapenem-resistant Acinetobacter baumannii and Klebsiella pneumoniae across a hospital system: impact of postacute care facilities on dissemination. J Antimicrob Chemother. 2010; 65(8):1807-18. doi: 10.1093/jac/ dkq191.

3. Hsu LY, Tan TY, Jureen R, Koh $\mathrm{TH}$, Krishnan P, Tzer-Pin Lin R, et al. Antimicrobial drug resistance in Singapore hospitals. Emerg Infect Dis. 2007;13(12):1944-7. doi: 10.3201/ eid1312.070299.

4. Prabaker K, Weinstein RA. Trends in antimicrobial resistance in intensive care units in the United States. Curr Opin Crit Care. 2011;17(5):472-9. doi: 10.1097/MCC.0b013e32834a4b03.

5. Berrazeg M, Diene SM, Medjahed L, Parola P, Drissi M, Raoult D, et al. New Delhi Metallo-beta-lactamase around the world: An eReview using Google Maps. Euro Surveill. 2014;19(20). pii:20809.

6. Queenan AM, Bush K. Carbapenemases: the versatile betalactamases. Clin Microbiol Rev. 2007;20(3):440-58. doi: 10.1128/ CMR.00001-07.

7. Muir A, Weinbren MJ. New Delhi metallo-beta-lactamase: a cautionary tale. J Hosp Infect. 2010;75(3):239-40. doi: 10.1016/j.jhin.2010.02.005.

8. Kumarasamy KK, Toleman MA, Walsh TR, Bagaria J, Butt F, Balakrishnan R, et al. Emergence of a new antibiotic resistance mechanism in India, Pakistan, and the UK: a molecular, biological, and epidemiological study. Lancet Infect. Dis. 2010; 10(9):597-602. doi: 10.1016/S1473-3099(10)70143-2.

9. Yong D, Toleman MA, Giske CG, Cho HS, Sundman K, Lee K, et al.
Characterization of a new metallo- $\beta$ lactamase gene, bla (NDM-1), and a novel erythromycin esterase gene carried on a unique genetic structure in Klebsiella pneumoniae sequence type 14 from India. Antimicrob. Agents Chemother. 2009;53(12),5046-54. doi: 10.1128/AAC.00774-09.

10. Nordmann P, Poirel L, Walsh TR, Livermore DM. The emerging NDM carbapenemases. Trends Microbiol. 2011;19(12):588-95. doi: 10.1016/j. tim.2011.09.005.

11. Maya JJ, Ruiz SJ, Blanco VM, Gotuzzo E, Guzman-Blanco M, Labarca J, et al. Current status of carbapenemases in Latin America. Expert Rev Anti Infect Ther. 2013;11(7): 65767.doi: 10.1586/14787210.2013.811924.

12. Pasteran F, Albornoz E, Faccone D, Gomez S, Valenzuela C, Morales $\mathrm{M}$, et al. Emergence of NDM-1producing Klebsiella pneumoniae in Guatemala. J. Antimicro Chemother. 2012;67(7):1795-7. doi: 10.1093/jac/ $\mathrm{dks} 101$.

13. Escobar Pérez JA, Olarte Escobar NM, Castro-Cardozo B, Valderrama Márquez IA, Garzón Aguilar MI, Martínez de la Barrera L, et al. Outbreak of NDM-1-producing Klebsiella pneumoniae in a neonatal unit in Colombia. Antimicrob Agents Chemother. 2013;57(4):1957-60. doi: 10.1128/AAC.01447-12.

14. Rogers B, Sidjabat H, Silvey A, Anderson T, Perera S, Li J, et al. Treatment Options for New Delhi Metallo-Beta-Lactamase- Harboring Enterobacteriaceae. Microb Drug Resist. 2013;19(2):100-3. doi: 10.1089/mdr.2012.0063.

15. Yigit H, Queenan AM, Anderson GJ, Domenech-Sanchez A, Biddle JW, Steward CD, et al. Novel carbapenemhydrolyzing-lactamase, KPC-1, from a carbapenem-resistant strain of Klebsiella pneumoniae. Antimicrob. Agents Chemother. 2001;45(4):115161. doi: 10.1128/AAC.45.4.11511161.2001.
16. Villegas MV, Lolans K, Correa A, Suarez CJ, López J, Vallejo M, et al. First Detection of the Plasmid-Mediated Class A Carbapenemase KPC-2 in Clinical Isolates of Klebsiella pneumoniae from South America. Antimicrob Agents Chemother. 2006;50(8):2880-2. doi: 10.1128/AAC.00186-06.

17. Velásquez J, Hernández R, Pamo $\mathrm{O}$, Candiotti M, Pinedo Y, Sacsaquispe R, et al. Klebsiella pneumoniae resistente a los carbapenemes. Primer caso de carbapenemasa tipo KPC en Perú. Rev Soc Peru Med Interna. 2013;26(4):1926.

18. Espinoza JC. Presencia de casos Klebsiella pneumoniae y/o Staphylococcus aureus meticilino resistente en pacientes del servicio de medicina del Hospital Antonio LorenaCusco. Alerta epidemiológica $\mathrm{N}^{\circ} 001$ 2016 marzo de 2016. Disponible en: http://www.diresacusco.gob. pe/inteligencia/epidemiologia/ alertas/alertas2016/ALERTA\%20 EPIDEMIOLOGICA\%20001-2016. pdf

19. Jain A, Hopkins K, Turton J, Doumith M, Hill R, Loy R, et al. NDM carbapenemases in the United Kingdom: an analysis of the first 250 cases. J Antimicrob Chemother 2014; 69(7):1777-84. doi: $10.1093 / \mathrm{jac} /$ dku084.

20. Hidalgo L, Hopkins KL, Gutierrez B, Ovejero CM, Shukla S, Douthwaite $S$, et al. Association of the novel aminoglycoside resistance determinant $\mathrm{RmtF}$ with NDM carbapenemase in Enterobacteriaceae isolated in India and the UK. J Antimicrob Chemother. 2013; 68(7):1543-50. doi: $10.1093 / \mathrm{jac} / \mathrm{dkt} 078$.

Correspondencia: Juan José Montenegro Idrogo Dirección: Av. Arnaldo Márquez 579, Int 507, Jesús María. Lima, Perú.

Correoelectrónico:montenegroidrogo@gmail.com 